Pesq. Vet. Bras. 29(2):174-176, fevereiro 2009

\title{
Soroprevalência da infecção leptospiral em capivaras (Hydrochoerus hydrochaeris) abatidas em um frigorífico do Rio Grande do Sul ${ }^{1}$
}

\author{
Éverton F. Silva ${ }^{2,3^{*}}$, Núbia Seyffert'2,3, Sandra D.D. Jouglard ${ }^{3}$, Daniel A. \\ Athanazio ${ }^{4}$, Odir A. Dellagostin ${ }^{3}$ e Claudiomar S. Brod ${ }^{2}$
}

\begin{abstract}
Silva E.F., Seyffert N., Jouglard S.D.D., Athanazio D.A., Dellagostin O.A. \& Brod C.S. 2009. [Seroprevalence of leptospiral infection in capybaras (Hydrochoerus hydrochaeris) in a slaughterhouse of Rio Grande do Sul, Brazil.] Soroprevalência da infecção leptospiral em capivaras (Hydrochoerus hydrochaeris) abatidas em um frigorífico do Rio Grande do Sul. Pesquisa Veterinária Brasileira 29(8):174-176. Laboratório do Centro de Controle de Zoonoses, Faculdade de Veterinária, Universidade Federal de Pelotas, 96010-900 Pelotas, RS, Brazil. E-mail: efsilva@ufpel.edu.br

Capybaras (Hydrochoerus hydrochaeris) are wild rodents from the American Continent with increasing importance as a commercial alternative source of meat for human consumption. Studies on seroprevalence for leptospiral infection are scarce and restricted to free living capybaras. We report detection of agglutinating antibodies against leptospires in 27\% (6/22) of all animals in a slaughterhouse from Rio Grande do Sul. The highest antibody titers predicted Australis as the infecting serogroup due to reactions against a reference strain of serovar Bratislava and a canine local isolate of serovar Australis, characterized as Leptospira noguchii. The data presented in this report highlight that a considerable fraction of capybaras in captivity may behave as reservoir for pathogenic leptospires emphasizing the occupational risk of those who deal with animal farming and slaughter.
\end{abstract}

INDEX TERMS: Leptospirosis, capybara, serology, agglutinins.

RESUMO.- Capivaras (Hydrochoerus hydrochaeris) são roedores selvagens do continente americano com crescente importância comercial como fonte alternativa de carne para o consumo humano. Nessa espécie, os estudos sobre a soroprevalência da infecção leptospiral são escassos e restritos aos espécimes de vida livre. Relatamos aqui reações positivas para anticorpos aglutinantes anti-leptospiras em $27,3 \%$ (6/22) das capivaras abatidas em um frigorífico do Rio Grande do Sul. Os níveis mais altos de anticorpos sugerem infecção pelo sorogrupo

\footnotetext{
${ }^{1}$ Recebido em 27 de dezembro de 2007.

Aceito para publicação em 9 de fevereiro de 2009.

2 Laboratório do Centro de Controle de Zoonoses, Faculdade de Veterinária, Universidade Federal de Pelotas (UFPel), Campus Universitário s/n, Cx. Postal 354, Pelotas, RS 96010-900, Brasil. *Autor para correspondência: efsilva@ufpel.edu.br

${ }^{3}$ Centro de Biotecnologia, UFPel.

${ }^{4}$ Depto Biointeração, Universidade Federal da Bahia, Av. Reitor Miguel Calmon s/n, Vale do Canela, Salvador, BA 40110-100, Brasil.
}

Australis devido à reação para uma cepa de referência do sorovar Bratislava e para um isolado canino local do sorovar Australis, caracterizado como Leptospira noguchii. Esses resultados ressaltam que considerável parcela de capivaras criadas em cativeiro podem funcionar como reservatório de leptospiras patogênicas e chamam atenção para o risco ocupacional dos trabalhos que envolvem a criação e o abate dessa espécie animal.

TERMOS DE INDEXAÇÃO: Leptospirose, capivara, sorologia, aglutininas.

\section{INTRODUÇÃO}

Leptospirose é uma zoonose de distribuição mundial com alta prevalência em países de clima tropical (Levett 2001). O estado do Rio Grande do Sul (RS) tem cerca de $11 \mathrm{mi}$ Ihões de habitantes e um típico clima temperado, entretanto, a prevalência da leptospirose humana no RS é maior que a média do restante do Brasil, onde predominam os climas tropical, subtropical e equatorial (12,5 versus 3,5 
casos por 100 mil habitantes em 2001). No RS, a maior parte (69\%) dos casos de leptospirose humana ocorre na zona rural e a distribuição espacial sugere associação com lavouras de arroz (Barcellos et al. 2003).

Capivaras (Hydrochoerus hydrochaeris) são roedores selvagens que estão distribuídos pelo continente americano desde o Panamá até o Uruguai. No Brasil, elas habitam áreas próximas a rios e lagoas. Com o desequilíbrio ecológico e as mudanças no seu habitat natural, elas ocasionalmente invadem lavouras e a periferia de áreas urbanas. Esses roedores são acentuadamente prolíferos; as fêmeas podem reproduzir a cada seis meses e gerar, em média, quatro filhotes por gestação (Cueto et al. 2000). Devido à viabilidade técnica, rentabilidade de criação e potencial zootécnico (Moreira \& MacDonald 2000), a carne de capivara ganhou importância econômica nos últimos anos (Andrade et al. 1998).

No Brasil, investigações sorológicas para detecção de infecção por leptospiras (Nogueira et al. 1997, Ito et al. 1998, Marvulo et al. 2002, Shimabukuro 2006) e isolamento de leptospiras (De Paula et al. 2001) têm sido realizados em capivaras a fim de demonstrar seu papel como reservatório dessas bactérias. Porém, todos esses estudos de infecção natural e outro de infecção experimental (Marvulo 2003) investigaram apenas capivaras de vida livre.

O objetivo deste estudo foi determinar o status sorológico da infecção por leptospiras em capivaras abatidas para consumo humano em um frigorífico do Rio Grande do Sul, Brasil.

\section{MATERIAL E MÉTODOS}

Foi realizado o abate de 22 capivaras em um frigorífico do município de Nova Bassano, no Rio Grande do Sul. Dessas 22 capivaras foram coletadas amostras de sangue. As capivaras foram identificadas com números crescentes conforme a localização na linha de abate e as amostras foram encaminhadas ao laboratório do Centro de Controle de Zoonoses da Faculdade de Veterinária da Universidade Federal de Pelotas (CCZ/ UFPel) para a avaliação do status sorológico utilizando teste de soroaglutinação microscópica com antígenos vivos (MAT), conforme recomendação prévia (Faine 1982).

As amostras foram processadas com uma diluição inicial do soro em solução salina tamponada (PBS), pH 7,2, na proporção de 1:50 e os soros foram distribuídos em microplacas com 96 cavidades. Os antígenos utilizados no experimento possuíam sete dias de crescimento em meio de cultura EMJH líquido (Laboratórios Difco, Porto Alegre, RS, Brasil) com a densidade de $1-2 \times 10^{8}$ leptospiras $/ \mathrm{mL}$ e foram mantidos a uma temperatura de $28-30^{\circ} \mathrm{C}$. Foram utilizados 50 sorovares leptospirais, um sorovar de Leptonema e três isolados locais.

As amostras foram consideradas reagentes quando houve aglutinação igual ou superior a 50\% em comparação ao controle. Quando positivas na triagem, as amostras foram tituladas até o maior título aglutinante. A partir do título de 100, as amostras dos animais foram consideradas positivas.

\section{RESULTADOS}

Das 22 amostras testadas, seis $(27,3 \%)$ foram reagentes no MAT e a variação entre os títulos de anticorpos encon-
Quadro 1. Resultados das amostras reagentes no MAT com os respectivos sorovares aglutinantes e títulos de anticorpos detectados

\begin{tabular}{lcccccc}
\hline \multicolumn{1}{c}{ Sorovares } & \multicolumn{7}{c}{ Amostras reagentes/Título de anticorpos } \\
\cline { 2 - 7 } & 4 & 5 & 9 & 16 & 20 & 22 \\
\hline Andamana & $-a$ & - & - & - & - & - \\
Australis & - & 400 & - & - & - & 800 \\
Australis (cepa Hook/ & 50 & 800 & 1.600 & - & - & 1.600 \\
$\quad$ isolado local) & & & & & & \\
Autumnalis & - & 50 & 50 & - & - & 400 \\
Bataviae & - & - & - & - & - & 50 \\
Bratislava & 100 & 800 & 1.600 & - & - & 3.200 \\
Copenhageni & - & 25 & - & - & - & - \\
Djasiman & - & 25 & - & - & - & - \\
Icterohaemorrhagiae & - & - & - & - & - & - \\
Leptonema illini & - & - & - & 200 & 200 & 50 \\
Panama & - & 400 & - & - & - & 400 \\
Patoc & - & - & - & - & - & 50 \\
Poi & - & - & - & - & - & - \\
Tarassovi & - & - & - & - & - & - \\
\hline
\end{tabular}

a. Não-reagentes.

trados foi de 100 a 3.200. O Quadro 1 apresenta os resultados das amostras reagentes com os respectivos sorovares aglutinantes e os títulos de anticorpos detectados. Em quatro casos, os títulos mais altos do MAT previram a infecção pelo sorogrupo Australis (pela reação com os sorovares Bratislava e Australis). O sorovar Australis reagente consiste num isolado canino local caracterizado genomicamente como Leptospira noguchii. Os dois casos restantes apresentaram reação unicamente para Leptonema illini, uma espiroqueta saprófita filogeneticamente próxima às leptospiras.

\section{DISCUSSÃO E CONCLUSÃO}

A positividade e os títulos expressivos para um isolado do ecossistema local reforçam a recomendação do uso de isolados locais no MAT (WHO 2003), já que a grande maioria dos sorovares constantes na bateria de diagnóstico do CCZ/ UFPel são oriundos de países com clima e fauna diferentes daqueles do Brasil. Os altos títulos de anticorpos aglutinantes contra um isolado local de cultura de rim de cão, caracterizado genomicamente como $L$. noguchii sorogrupo Australis (cepa Hook) (Silva et al. 2008), chama atenção para a possibilidade da circulação de $L$. noguchii em capivaras. Isolados de Leptospira noguchii já foram obtidos nas áreas rurais e urbanas de Pelotas, RS, a partir de humanos, cães e ovinos (Silva et al. 2007, Silva et al. 2008). Esta espécie não havia sido, até então, relacionada à infecção de capivaras.

No Brasil, apenas um isolamento a partir de capivara foi relatado e a cepa não foi caracterizada (De Paula et al. 2001). O estudo da soroprevalência para anticorpos aglutinantes em capivaras de vida livre identificou uma taxa de $33 \%$ no pantanal sul-matogrossense (Ito et al. 1998) e 30\%$56 \%$ na região de Piracicaba, São Paulo (Nogueira et al. 1997, De Paula 2003). Em São Paulo, 60\% (27/45) das capivaras da área metropolitana do alto Tietê apresentaram sorologia positiva, enquanto esta taxa foi de 35\% (12/ 
34) em capivaras de zonas rurais paulistas (Shimabukuro 2006). Nos estudos paulistas, os sorogrupos previsto pelos títulos mais altos do MAT apresentam resultados bastantes variáveis com predomínio do sorogrupo Butembo em Piracicaba (Nogueira et al. 1997) e Icterohaemorrhagiae no município de São Paulo (Shimabukuro 2006).

A reatividade do MAT para cepas saprófitas não é um achado inesperado. Cepas saprófitas são utilizadas nas baterias de antígenos vivos de leptospiras como um "sinal de alerta" para o diagnóstico de leptospirose humana e geralmente títulos elevados para estes organismos são interpretados como reação cruzada com novos sorovares patogênicos da região que ainda não foram incluídos na bateria (Rudy Hartskeerl, comunicação pessoal).

A infecção por leptospiras patogênicas em animais criados para produção de alimentos é um problema reconhecido mundialmente. No Brasil, investigações recentes com bovinos sugerem uma soroprevalência que varia entre $16 \%$ e $47 \%$ de acordo com as regiões do país (Oliveira et al. 2001, Lilenbaum \& Souza 2003, Thompson et al. 2006). Mesmo em países desenvolvidos, o problema persiste como foi recentemente relatado em uma avaliação de 1.193 bovinos abatidos no Texas, Estados Unidos. Nesse estudo, a soroprevalência foi de $22 \%$ para o sorovar Pomona e de $15 \%$ para o sorovar Hardjo. No mesmo estudo, a avaliação de 300 amostras de urina identificou, por reação em cadeia da polimerase (PCR), o DNA de Leptospira em 35\% de todos os bovinos (Talpada et al. 2003).

Em nosso estudo, os títulos de anticorpos para os sorovares testados revelam que considerável parcela do lote de capivaras abatido poderia apresentar leptospiras no sangue, nos tecidos e na urina. Portanto, os funcionários dos criatórios e os magarefes de frigoríficos onde essas capivaras vivem e são abatidas necessitam ser orientados sobre os cuidados que devam ser tomados no contato com esses roedores e com os produtos derivados dessa espécie.

Agradecimentos.- À Profa. Maria Fernanda Vianna Marvulo, da Universidade Paulista, pelo auxílio no acesso a importantes referências bibliográficas necessárias para realização deste estudo, e a Guilherme Becker, Gustavo Cerqueira, Fabiana Seixas e Tiago Collares pelo auxílio na coleta e processamento das amostras. Este trabalho teve apoio financeiro do CNPq (Proc. 558309/2008-9).

\section{REFERÊNCIAS}

Andrade P.C.M., Lavoreneti A. \& Filho S.L.G.N. 1998. Efeitos do tamanho da área, da dieta e da idade inicial de confinamento sobre capivaras (Hydrochaeris hydrochaeris) em crescimento. Revta Bras. Zootec. 27:292-299.

Barcellos C., Lammerhirt C.B., Almeida M.A. \& Santos E. 2003. Distribuição espacial da leptospirose no Rio Grande do Sul, Brasil: recuperando a ecologia dos estudos ecológicos. Cad. Saúde Publica 19:12831292.

Cueto G.R., Allekotte R. \& Kravetz F.O. 2000. Scurvy in capybaras bred in captivity in Argentine. J. Wildl. Dis. 36:97-101.
De Paula C.D. 2003. Dinâmica populacional da leptospirose em capivaras (Hydrochaeris hydrochaeris) de vida livre. Dissertação de Mestrado em Epidemiologia Experimental Aplicada às Zoonoses, USP, São Paulo, SP. 65p.

De Paula C.D., Marvulo M.F.V. \& Miraglia F. 2001. Isolamento de leptospira em capivaras (Hydrochaeris hydrochaeris) de vida livre. Anais do V Congresso e X Encontro da Associação Brasileira de Veterinários de Animais Selvagens, São Paulo, SP, s/p.

Faine S. 1982. Guidelines for the control of leptospirosis. World Health Organization, Geneva. 171p.

Ito F.H., Vasconcelos S.A., Bernardi F., Nascimento A.A., Labruna M.B. \& Arantes I.G. 1998. Evidencia sorológica de brucelose e leptospirose e parasitismo por ixodídeos em animais silvestres do Pantanal Sul-Matogrossense. Ars Vet. 13:302-310.

Levett P.N. 2001. Leptospirosis. Clin. Microbiol. Rev. 14:296-326.

Lilenbaum W. \& Souza G.N. 2003. Factors associated with bovine leptospirosis in Rio de Janeiro. Brazil. Res. Vet. Sci. 75:249-251.

Marvulo M.F.V. 2003. Leptospirose experimental em capivaras (Hydrochaeris hydrochaeris) com Leptospira interrogans variante sorológica pomona. Dissertação de Mestrado em Epidemiologia Experimental Aplicada às Zoonoses, USP, São Paulo, SP. 35p.

Marvulo M.F.V., Paula C.D., Ferreira P.M., Morais Z.M., Delbem A.C.B., Fávero A.C.M., Miraglia F., Castro V., Genovez M.E., Ferraz K., Verdade L.M., Fellipe P.A.N., Ferraz E., Penteado M., Ferreira Neto J.S., Ferreira F. \& Vasconcellos S.A. 2002. Detection of Leptospira in two free living populations of capybaras (Hydrochaeris hydrochaeris) from São Paulo state, Brazil. Proc. 3rd Scient. Meet. Int. Lepospirosis Society, Barbados, s/p.

Moreira J.R. \& MacDonald D. 2000. Capybara use and consevation in South America. Bull. Bedim 9:2-19.

Nogueira M.F., Langoni H., Lavorenti A., Gimenes S.M. \& Nogueira Filho S.L.G. 1997. Detecção de anticorpos anti-Leptospira spp. e antiBrucella abortus em capivaras (Hydrochaeris hydrochaeris). Anais do XIX Congresso Brasileiro de Microbiologia, Rio de Janeiro, RJ, s/p.

Oliveira A.A.F., Mota R.A., Pereira G.C., Langoni H., Souza M.I., Navegantes W.A. \& Sa M.E.P. 2001. Seroprevalence of bovine leptospirosis in Garanhuns municipal district, Pernambuco state, Brazil. Onderstepoort J. Vet. Res. 68:275-279.

Shimabukuro J.S. 2006. Estudo da soroprevalência de Leptospira spp. em capivaras (Hydrochaeris hydrochaeris) na bacia hidrográfica do Alto Tietê, SP. Dissertação de Mestrado em Epidemiologia Experimental Aplicada às Zoonoses, USP, São Paulo, SP. 50p.

Silva E.F., Brod C.S., Cerqueira G.M., Bourscheidt D., Seyffert N., Queiroz A., Santos C.S., Ko A.I. \& Dellagostin O.A. 2007. Isolation of Leptospira noguchii from sheep. Vet. Microbiol. 121:144-149.

Silva E.F., Santos C.S., Athanazio D.A., Seyffert N., Seixas F.K., Cerqueira G.M., Fagundes M.Q., Brod C.S., Dellagostin O.A. \& Ko A.I. 2008. Characterization of virulence of Leptospira isolates in a hamster model. Vaccine 26:3892-3896.

Talpada M.D., Garvey N., Sprowls R., Eugster A.K. \& Vinetz J.M. 2003. Prevalence of leptospiral infection in Texas cattle: implications for transmission to humans. Vector Borne Zoonotic Dis. 3:141-147.

Thompson J.A., Miranda Henriques Leite R., Goncalves V.S., Leite R.C., Bandeira D.A., Herrmann G.P., Moreira E.C., Prado P.E., Lobato Z.I., Brito C.P. \& Lage A.P. 2006. Spatial hierarchical variances and age covariances for seroprevalence to Leptospira interrogans serovar hardjo, BoHV-1 and BVDV for cattle in the state of Paraiba, Brazil. Prev. Vet. Med. 76:290-301.

WHO 2003. Human Leptospirosis: guidance for diagnosis, surveillance and control. World Health Organization Library Cataloguing-inPublication Data. 